\title{
Keratokonus Progresyonunun Önlenmesinde Korneal Kollajen Çapraz Bağlama Tedavisinin Etkinliği
}

\section{The Efficacy of Corneal Collagen Cross-Linking for the Treatment of Progressive Keratoconus}

Sibel İnan ${ }^{1}$

Ersan Çetinkaya ${ }^{2}$,

Resat Duman',

Bünyamin Kutluksaman ${ }^{3}$,

Mustafa Doğan',

Güliz Fatma Yavaş ${ }^{4}$

'Afyon Kocatepe Üniversitesi Göz Hastalıkları Anabilim Dalı, Afyonkarahisar

¿Manisa Devlet Hastanesi Göz Hastalıkları Kliniği. Manisa

${ }^{3}$ Niksar Devlet Hastanesi Göz Hastalıkları Kliniği, Tokat

${ }^{4}$ Hacettepe Üniversitesi Göz Hastalıkları Anabilim Dalı, Ankara

Geliş Tarihi/Received: 29 Ağustos 2017

\begin{abstract}
Öz
Amaç: Illerleyici keratokonusu bulunan hastalarda korneal kollajen çapraz bağlama tedavisinin etkinliğinin araştırılması amaçlanmıştır

Hastalar ve Yöntem: Çalışmaya altııı bayan, dördü erkek 10 hastanın keratokonus değerlerinde ilerleme saptanan 10 gözü dahil edilmiştir. Tüm hastaların düzeltilmemiş ve en iyi düzeltilmiş görme keskinlikleri, biyomikroskobik muayene, göz içi basınç ölçümü içeren tam oftalmolojik muayeneleri yapılmış ve korneal topografi ölçümleri gerçekleştirilmiştir. Topografi ölçümleri Sirius Korneal topografi cihazı ile gerçekleştirildi. Tüm hastalara riboflavin/UV-A ile kornea kollajen çapraz bağlama işlemi gerçekleştirilmiştir. Bulgular: 6 aylık takip süresinin sonunda, korneal topografide, tüm hastaların Sim K max değeri ortalama $0,95 \pm 0,22 \mathrm{D}$ azalma göstermiştir. Sim K min değeri ise 8 gözde (\%80) azalırken (ortalama 0,39 D) 2 gözde (\%20) değişiklik olmamıştır. Santral kornea kalınlıkları ise ortalama 10,1 $1,37 \mu \mathrm{m}$ azalma göstermiştir. En iyi düzeltilmiş görme keskinlikleri tedavi öncesi ve sonrasına göre incelendiğinde 6 hastada $(\% 20)$ tedav öncesine göre artış gösterdiği, 4 hastada (\%40) ise görme keskinliklerinin sabit kaldığı tespit edilmiştir. Sonuç: Apollon cihazı ile kliniğimizin ilk uygulamalarının sonuçlarına göre korneal kollajen çapraz bağlama tedavisi keratokonus progresyonunu durdurmada etkili bir yöntem olarak görünmektedir. Tedavinin kalıcılığının değerlendirilebilmesi için uzun dönemli geniş serili, prospektif çalışmalara ihtiyaç duyulmaktadır.
\end{abstract}

Anahtar Kelimeler: Keratokonüs, Progresyon, Korneal Kollajen Çapraz Bağlama, Riboflavin

\begin{abstract}
Aim: The aim of the study was to investigate effectiveness of corneal collagen cross-linking treatment in patients with progressive keratoconus.

Patients and Methods: Ten patients ( 6 female and 4 male) who showed progression in the parameters of Keratoconus were included in the study. Complete ophthalmological examinations including uncorrected and best-corrected visual acuities (UCVA and BCVA), slit-lamp anterior and posterior segment investigation and intraocular pressure was performed in all patients. Corneal topographic measurements were done by Sirius Corneal Topography system. All patients underwent an intervention of corneal collagen crosslinking procedure with riboflavin and UV-A.

Results: Sim K max value of all patients in topographic measurement decreased (mean 0,95 $\pm 0,22 \mathrm{D}$ ) after 6 month follow-up. The value of sim $\mathrm{K}$ min decreased (mean $0.39 \mathrm{D}$ ) in 8 patients, while it showed no change in 2 patients $(20 \%)$. A decrease of mean of $10,1 \pm 1,37 \mu \mathrm{m}$ central corneal thickness was observed In 6 eyes $(60 \%)$, BCVA showed improvement when compared to the baseline values, while BCVA in 4 $(40 \%)$ eyes remained stable during the follow-up period.

Conclusion: Corneal collagen cross-linking treatment as a first applications of our clinic using Apollon device seems to be effective in prevention of keratoconus progression according to our experience in our small series. Long-term, prospective, large studies are needed to display the long-term effectiveness of this treatment.
\end{abstract}

Key Words: Keratoconus, Progression, Corneal Collagen Cross-Linking, Riboflavin

\section{GíRiş}

Keratokonus parasantral korneal incelme ile beraber düzensiz korneal astigmatizma, ilerleyici miyopi ve görme kaybı ile karakterize noninflamatuar korneal dejeneratif bozukluktur (1). Toplumda 2000 kişide 1 şeklinde insidansı olduğu düşünülmektedir. Keratokonusta korneada santral ve parasantral progresif incelme ve protrüzyon oluşur. Böylece korneada koni şekli meydana gelir (2). Daha çok puberte döneminde tanısı konulmakta ve bazı gözlerde keratoplastiye kadar giden hastalığın ilerleyici olması nedeniyle takibi gerekmektedir. Keratokonusun etyolojisinde genetik yatkınlık ve çevresel faktörler önemli yer tutar. Kalıtsal paterni net değildir fakat hastaların \%6-8'inde aile hikayesi bulunmaktadır. Keratokonus birçok oftalmik ve sistemik hastalıklarla birlikte görülebilir. Genelllikle olgular bilateraldir. Fakat bir gözün etkilenmesi daha
Yazışma Adresi: Sibel Inan, Afyon Kocatepe Universitesi Tıp Fakültesi Göz Hastalıkları Anabilim Dalı Merkez/Afyonkarahisar

e-posta: drinan33@gmail.com

Atıf yapmak için: Inan S, Çetinkaya E, Duman R, Kutluksaman B, Doğan M, Yavaş GF. Keratokonus Progresyonunun Önlenmesinde Korneal Kollajen Çapraz Bağlama Tedavisinin Etkinliği Selcuk Med J 2018;34(3): 106-111
Açıklama: Yazarların hiçbiri, bu makalede bahsedilen herhangi bir ürün, aygıt veya ilaç ile ilgili maddi çıkar ilişkisine sahip değildir. Araștırma, herhangi bir dis organizasyon tarafından desteklenmedi. Yazarlar calısmanin birincil verilerine tam erisim izni vermek ve derginin talep ettiği takdirde verileri incelemesine izin vermeyi kabul etmektedirler. 
çok olabilir. Bazen daha az etkilenen göz sadece yüksek astigmatizma gösterir ve bu durum hastalığın minimal seviyede ortaya çıkan bulgusu olabilir. $\mathrm{Bu}$ hastalık 20-30 'lu yaşlarda ilerleme eğiliminde olmasının yanında herhangi bir zamanda da ilerleme meydana gelebilir. Hastalığın ilerlemesiyle santral kornea apeksindeki incelme giderek kötüleşir ve ileri derecede irregüler astigmatizma meydana gelir (3). Tedavi basamak şeklinde düzenlenmelidir. Cerrahi dışı tedavi seçenekleri denenmeli, başarısızlık durumunda ise cerrahi tedaviye başvurulmalıdır.

Santral korneal skar gelişmesi durumunda ise penetran ya da lameller keratoplasti gerekmektedir. Hastalığın progresyonunu önlemede ileri sürülmüş tek tedavi seçeneği kollajen çapraz bağlama tedavisidir. Riboflavin/UV-A ile kollajen çapraz bağlama tedavisinde, fotosensitif bir madde olan riboflavin ve $370 \mathrm{~nm}$ dalga boyunda UV-A kullanılır. UV-A ile riboflavin kollajen fibrillerin amino gruplarının birbirine bağlanmasını sağlayan reaktif oksijen türleri ve süperoksid anyon radikalleri oluşumunu sağlar. Keratokonusta kollajen lifler arasında çapraz bağlar azalır ve bunun sonucunda kornea stromasının biyomekanik gücü zayıflar. Riboflavin/UV-A ile kornea kollajen lifleri arasında çapraz bağ oluşturulur (4). Korneanın biyomekanik gücü artar. UV-A ışınının kornea endoteline radyasyon hasarı vermemesi için kornea stromasının sadece $300 \mu$ m'lik ön kısmı tedavi edilir. Standart tedavide korneal epitel debridmanı sonrası $\% 0,1^{\prime}$ lik riboflavin solüsyonu her 3 dakikada bir 30 dakika uygulanır ve sonra 30 dakika süresince UV-A uygulanır (5). Tedavi etkinliği kornea topografisi ve konfokal mikroskopi ile değerlendirilebilir. Çapraz bağlama tedavisinde riboflavin (vitamin B2) göz damlası kornea stroması boyunca absorbe edilerek UV-A aracılığıyla fotokimyasal reaksiyonları tetikleyerek stromada kollajen fibriller arasında güçlü kovalent bağlar oluşturmaktadır (6-9).

Çalışmamızda hastalığı ilerleme gösteren keratokonus hastalarında, korneal çapraz bağlama tedavisi uygulaması sonuçlarını değerlendirmek amaçlanmıştır. Bu çalışma ilk yerli üretim çapraz bağlama cihazı ile gerçekleştirilmiş olan ve kliniğimizdeki ilk uygulamaların sonuçlarının verildiği pilot bir çalışmadır.

İstatistiki analizlerde SPSS versiyon 22.00 ( SPSS, Inc Chicago, IL) kullanılmıştır. Değişkenler ortalama土 standart deviasyon olarak belirtilmiştir. Değişkenlerin dağılımı Kolmogorov-Smirnov testi ile, tedavi öncesi ve sonrası değerler nonparametrik paired $t$ testi (Wilcoxon signed ranks test) ile değerlendirilmiştir.
İstatiksel olarak $p<0,05$ değerleri anlamlı kabul edilmiştir.

\section{HASTALAR VE YÖNTEM}

$\mathrm{Bu}$ çalışma Helsinki deklarasyon prensiplerine uygun bir şekilde tasarlanmış ve yürütülmüştür. Çalışmamıza başlamadan önce Afyon Kocatepe Üniversitesi Tıp Fakültesinden 127 karar numarası ile etik kurul onayı alınmıştır. Çalışmaya dahil edilmesi planlanan hastalar bilgilendirilerek, yazılı onamları alınmıştır. Yaş ortalaması 21 olan, altısı bayan dördü erkek 10 ilerleyici keratokonus hastasının 10 gözü çalışmaya dahil edilmiştir.

Hasta takipleri sırasında ilerleme göstergesi olarak en az bir parametrenin bulunması koşulu aranmıştır. Bu parametreler: 1) Son 1 yıl içerisinde maksimum keratometri değerinin en az 1 diyoptri (D) artması; 2) Manifest refraksiyonda sferik eşdeğerinin en az 0,5 D artması; 3) Manifest refraksiyonda astiğmatik değerin en az 1 D artması. 4) Son 1 yıl içinde kornea kalınlığında en ince noktada 30 mikron incelmedir.

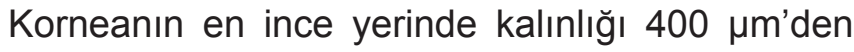
az olan, kornea skarı olan, önceden geçirilmiş herhangi bir kornea cerrahisi öyküsü olan, oküler yüzey hastalık öyküsü olan hastalar çalışmaya dahil edilmemiştir. Tüm katılımcılara detaylı bir oftalmolojik muayene yapılmıştır. Düzeltilmemiş ve düzeltilmiş en iyi görme keskinleri (EDGK), biyomikroskopik ön ve arka segment muayeneleri, göz içi basınç ölçümleri, kornea topografisi parametreleri (simüle en dik keratometrik değer (Sim K max), simüle en düz keratometrik değer (im K min), santral korneal kalınlık) değerlendirilmiştir. Topografik ölçümler kombine Scheimpflug-Placido topografi cihazı (Sirius, CSO Inc, İtalya) ile yapılmıştır. Hastalara \% 0.1 riboflavin, \%20 dekstran T500 içinde (Merribo İso-Osmolar, Meran Medikal,Türkiye) ve UV-A (Apollon, Meran Medikal, Türkiye) ile standart korneal çapraz bağlama tedavisi uygulanmıştır. Tedavi öncesi ölçümler tedavi sonrası 6. ay değerleriyle karşılaştırılmıştır.

\section{Korneal çapraz bağlama tedavisi uygulaması}

Tüm hastalara operasyondan önce onar dakika arayla üç kez topikal \% 0,5'lik proparakain $\mathrm{HCl}$ oftalmik solüsyon (Alcaine ${ }^{\circledR}$, Alcon, ABD) damlatılarak oküler yüzey anestezisi sağlanmıştır. Periokuler bölge \% 5 povidoniyodin ile temizlenip steril örtü ile kapatılmıştır. Blefarosta ile kapaklarda yeterli açıklık sağlanmıştır. Kornea kalınlığı ultrasonik pakimetre (Accutome, AccuPachVI pakimetre, ABD) ile santral alanda en az 3 defa ölçüldükten sonra en ince kornea kalınlığı dikkate alınarak santral korneada $8 \mathrm{~mm}$ 
çapındaki alana 30 saniye süre ile \% 20’lik alkol uygulanıp, epitel spatul yardımı ile debride edilmiştir. Pakimetre ile kornea kalınlığı aynı noktadan tekrar ölçülmüştür. Sonrasında debride edilen bölgeye 30 dakika boyunca ortalama her üç dakikada bir \% 0.1 riboflavin, \%20 dekstran T500 içinde (Merribo İsoOsmolar, Meran Medikal, Türkiye) tatbik edilmiştir. Biyomikroskop yardımıyla ön kamaraya riboflavin geçişi tespit edildikten sonra, önce kornea kalınlığı tespiti yapılmış, $400 \mu \mathrm{m}$ üzerinde değer görülünce uygulamaya başlanmıştır. UV-A cihazı (Apollon, Meran Medikal, Türkiye) parametreleri $\left(370 \mathrm{~nm}, 3 \mathrm{mw} / \mathrm{cm}^{2}\right)$ ayarlandıktan sonra, 30 dakika boyunca ışın tedavisi gerçekleştirilmiştir. Bu uygulama sırasında debride bölgeye yine 3 dakikada bir riboflavin damlatılmaya devam edilmiştir. Uygulama bitince hastanın gözüne bir damla antibiyotik damlattıktan sonra tedavi amaçlı yumuşak kontakt lens yerleştirilmiştir (Bausch\&LombPureVision ${ }^{\mathrm{TM}}$, Rochester, New York). Postoperatif dönemde moksifloksasin \% 0,3 oftalmik solüsyon (Vigamoks, Alcon Inc, Texas, ABD) 4x1 (2 hafta), deksametazon \% 1 (Dexasine-SE, Liba İlaç) oftalmik solüsyon (epitel iyileşmesi tamamlandıktan sonra başlanmak üzere 1. Hafta $4 \times 1,2$. Hafta $3 \times 1$, 3. Hafta $2 \times 1,4$. Hafta 1x1) ve prezervansız suni göz yaşı preparatı Systane Ultra (Alcon, Fort Worth, TX) tedavileri başlanmıştır (4x1, 4 hafta). Epitelizasyon tamamlandıktan sonra kontakt lensi çıkarılan hastalar 1,3 ve 6 . ayda kontrollere çağırılmıştır.

\section{BULGULAR}

Keratokonus tanısıyla kliniğimizde takip ettiğimiz, progresyon gösteren 10 hastanın 10 gözü çalışmaya dahil edildi. Standart crosslinking prosedürü uygulandı. Hastalar 1,3 ve 6. aylarda takipleri yapıldı.6 aylık takip süresinin sonunda korneal topografide Sim K max değeri tüm hastalarda ortalama 0,95 $\pm 0,22 \mathrm{D}$ azalma göstermiştir ( $p=0,005)$. Sim K min değeri ise 8 gözde (\% 80) azalırken (ortalama 0,39D) 2 gözde (\% 20) değişiklik olmamıştır. Tüm gözler değerlendirildiğinde SimK min 0,29 $\pm 0,34 \mathrm{D}$ azalma göstermiştir $(p=0,021)$. Santral kornea kalınlıkları ise ortalama $10,1 \pm 1,37 \mu \mathrm{m}$ azalma göstermiştir $(p=0,005)$. En iyi düzeltilmiş görme keskinlikleri tedavi öncesi ve sonrasına göre incelendiğinde 6 hastanın (\% 60) tedavi öncesine göre artış gösterdiği 4 hastanın (\% 40) ise görme keskinliklerinin sabit kaldığı tespit edilmiştir (Tablo 1). EDGK değerlendirildiğinde ortalama $0,06 \pm 0,05$ artış göstermiştir( $p=0,014)$. Takiplerde hiçbir hastada önemli komplikasyon tespit edilmemiştir.

\section{TARTIŞMA}

Keratokonusta korneada meydana gelen konikleşme keratometrik ve refraktif değişimlere neden olmaktadır ve bu durum görme keskinliğini azaltmaktadır (10). Günümüzde bu hastalığın progresyonunu durdurmak için korneal çapraz bağlama tedavisi uygulanmaya başlanmıştır.

Korneal kollajen çapraz bağlama tedavisi ilk olarak Wollensak et al. (8) tarafından tarif edilmiştir. Bu uygulamada 370 nm'de UV-A ışını ve riboflavin yardımıyla kornea stromasında reaktif oksijen radikalleri oluşturulur ve bunlar kollajen fibrilleri arasında kimyasal kovalent bağlar oluşmasına sebep olurlar. Korneanın ön 300 mikron mesafesinde bu çapraz bağların daha yoğun olarak meydana geldiği de gösterilmiştir.

Korneal çapraz bağlama tedavisi çeşitli araştırmacılar tarafından geliştirilmeye çalışılmıştır. $\mathrm{Bu}$ tedavi temel prensipler aynı kalarak çeşitli tekniklerle gerçekleştirilmiştir $(11,12)$.

Witta-Silva et al. (11) yaptıkları çalışmada Kmax değerindeki ortalama azalma 6. ayda 0,92 ve 12 . ayda ise 1,45 olarak bulunmuştur. En iyi düzeltilmiş görme keskinliği de takip süresi boyunca artmış olarak bulunmuştur. Çalışmamızda da Sim K max. değerinde 6. ayda ortalama $0,95 \pm 0,22 \mathrm{D}$ azalma tespit edilmiştir. Coskunseven et al. (13) yaptığı çalışmada Sim Kmax değerinde ortalama 1,57 D azalma tespit edilmiştir. Gümüş et al. (14) yaptığı çalışmada ortalama 3,5 ay takip süresince Kmax değerinde beş hastada ortalama 1,18 D azalma, beş hastada ortalama 1,67 D artış ve iki hastada da değişmeyen değerler tespit edilmiştir. Aynı çalışmada EDGK dört hastada artmış, altı hastada sabit kalmış ve iki hastada azalma şeklinde tespit edilmiştir.

Çalışmamızda santral kornea kalınlığında 6

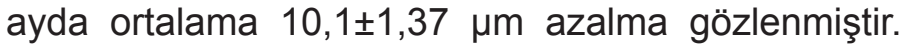
Vinciguerra et al. (15) yaptıkları çalışmada kornea kalınlığında 12 ayda önemli derecede azalma tespit etmişlerdir. Greenstein et al. (16) yaptıkları randomize kontrollü çalışmada ise pakimetrik ölçümlerde ilk aylarda meydana gelen azalmanın 1 yıl sonra tedavi öncesi değerlerine geri döndüğünü saptamışlardır.

Korneal çapraz bağlama tedavisi ile ilgili olarak prospektif yada retrospektif dünya çapında çeşitli araştırmalar yayınlanmıştır (17-20).

Henriquez et al. (21) yaptıkları çalışmada Kmax değeri kontrol grubu ile kıyasladığında 12. ayda ort. $2.21 \mathrm{D}$ fark bulmuşlardır. Tomita et al. (22) yaptıkları 48 gözün dahil edildiği çalışmada standart protokol ve hızlandırılmış protokol uygulanan gruplarda 1 yıllık 
Table 1. Hastaların tedavi öncesi ve sonrası topografik parametre, korneal kalınlık ve en iyi düzeltilmiş görme keskinlik değerleri

\begin{tabular}{|c|c|c|c|c|}
\hline Hasta No & Parametreler & Tedavi Öncesi & Tedavi sonrası & Takip süresi \\
\hline \multirow[t]{4}{*}{1} & Sim Kmax & 53,00 & 51,72 & 6 ay \\
\hline & Sim Kmin & 48,83 & 48,95 & \\
\hline & Korneal Kalınlık & 449 & 440 & \\
\hline & EDGK & 0,6 & 0,7 & \\
\hline \multirow[t]{4}{*}{2} & Sim Kmax & 49,89 & 48,80 & 6 ay \\
\hline & Sim Kmin & 47,01 & 46,88 & \\
\hline & Korneal Kalınlık & 463 & 454 & \\
\hline & EDGK & 0,8 & 0,8 & \\
\hline \multirow[t]{4}{*}{3} & Sim Kmax & 49,66 & 48,58 & 6 ay \\
\hline & Sim Kmin & 48,16 & 48,04 & \\
\hline & Korneal Kalınlık & 474 & 462 & \\
\hline & EDGK & 0,8 & 0,8 & \\
\hline \multirow[t]{4}{*}{4} & Sim Kmax & 55,05 & 54,10 & 6 ay \\
\hline & Sim Kmin & 52,45 & 52,45 & \\
\hline & Korneal Kalınlık & 432 & 422 & \\
\hline & EDGK & 0,6 & 0,7 & \\
\hline \multirow[t]{4}{*}{5} & Sim Kmax & 53,82 & 52,64 & 6 ay \\
\hline & Sim Kmin & 51,00 & 50,80 & \\
\hline & Korneal Kalınlık & 453 & 442 & \\
\hline & EDGK & 0,7 & 0,8 & \\
\hline \multirow[t]{4}{*}{6} & Sim Kmax & 51,53 & 50,91 & 6 ay \\
\hline & Sim Kmin & 48,56 & 48,56 & \\
\hline & Korneal Kalınlık & 447 & 436 & \\
\hline & EDGK & 0,7 & 0,8 & \\
\hline \multirow[t]{4}{*}{7} & Sim Kmax & 48,24 & 47,54 & 6 ay \\
\hline & Sim Kmin & 44,81 & 44,54 & \\
\hline & Korneal Kalınlık & 500 & 490 & \\
\hline & EDGK & 0,8 & 0,9 & \\
\hline \multirow[t]{4}{*}{8} & Sim Kmax & 48,19 & 47,48 & 6 ay \\
\hline & Sim Kmin & 44,92 & 44,15 & \\
\hline & Korneal Kalınlık & 492 & 483 & \\
\hline & EDGK & 0,8 & 0,8 & \\
\hline \multirow[t]{4}{*}{9} & Sim Kmax & 50,32 & 49,40 & 6 ay \\
\hline & Sim Kmin & 47,79 & 46,92 & \\
\hline & Korneal Kalınlık & 489 & 481 & \\
\hline & EDGK & 0,8 & 0,9 & \\
\hline \multirow[t]{4}{*}{10} & Sim Kmax & 50,91 & 49,85 & 6 ay \\
\hline & Sim Kmin & 48,40 & 47,75 & \\
\hline & Korneal Kalınlık & 494 & 482 & \\
\hline & EDGK & 0,9 & 0,9 & \\
\hline
\end{tabular}

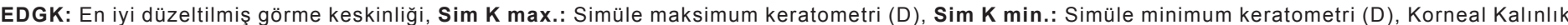
(mikron)

takipte Kmax değeri ve EDGK değerlerinde düzelme gözlenmiştir. Shetty et al. (23) yaptıkları 138 gözün dahil edildiği 1 yıllık takipli çalışmada hem standart hem de hızlandırımış protokoldeki çapraz bağlama tedavilerinde $\mathrm{K}$ max değerinde ve EDGK değerlerinde iyileşme göstermişlerdir. Bizim çalışmamızda da standart tedavi uyguladığımız hastalarımızda 6 aylık izlemimizde daha önceki çalışmalarla benzer şekilde Kmax ve EDGK değerlerinde düzelme gözlenmiştir.

Shalchi et al. (24) çalışmasında vakaların \% 8,133,3 arasında ortaya çıkan tedavi başarısızlığı, genellikle preoperatif Kmax değerinden $1 \mathrm{D}$ üzerinde artışla devam eden progresyon olarak tanımlanmıştır. Poli et al. (25) 6 yıllık izlem periyodunda \% 11 oranında tedavi başarısızığı rapor etmişlerdir. Çalışmamızda ise kısa süreli izlem periyodu bulunmaktadır.

Li et al. (26) yaptıkları bir metaanaliz çalışmasında minimum, maksimum ve ortalama keratometri değerlerinde kontrol grubuyla karşılaştırıldığında önemli ölçüde azalma gerçekleştiği gösterilmiştir. EDGK düzeyi ise kontrol grubu ile kıyaslandığında önemli derecede düzelme gösterdiği, düzeltilmemiş görme keskinliğinin ise istatistiksel olarak anlamlı değişmediği gösterilmiştir. Santral kornea 
kalınlığındaki değişiklikler ise istatistiksel olarak anlamlı bulunmamıştır.

Abbouda et al. (27) yaptıkları çalışmada korneal çapraz bağlama tedavisini izleyen çeşitli infektif keratit vakaları da gösterilmiştir. Standart korneal çapraz bağlama tedavisi sonrası diffüz lameller keratit, korneal incelme, persistan korneal ödem gibi nadir ciddi yan etkiler de rapor edilen çalışmalarda bulunmaktadır (28-30). Bizim çalışmamızda herhangi komplikasyon bulgusuna rastlanmamıştır.

Sonuç olarak korneal çapraz bağlama tedavisi keratokonus progresyonunu durdurmada etkili bir yöntem olarak görünmektedir. Tedavinin kalıcılığının değerlendirilebilmesi için uzun dönemli geniş serili prospektif çalışmalara intiyaç duyulmaktadır.

Bilgi: "Bu çalışma Afyon Kocatepe Üniversitesi Bilimsel Araştırma Projeleri Komisyonu tarafından 13.TIP.06 proje numarası ile desteklenmiştir."

Çıkar Çatışması: Çalışmada herhangi bir çıkar çatışması yoktur.

Finansal Çıkar Çatışması: Çalışmada herhangi bir finansal çıkar çatışması yoktur.

Yazışma Adresi: Sibel İnan,

Adres: Afyon Kocatepe Üniversitesi Tıp Fakültesi Göz Hastalıkları Anabilim Dalı Merkez/Afyonkarahisar

Email: drinan33@gmail.com Tel: 5058736689

\section{KAYNAKLAR}

1. Krachmer JH, Feder RS, Belin MW. Keratoconus and related non-inflammatory corneal thinning disorders. Surv Ophthalmol 1984;28:293-322.

2. Lembach RG. Use of contact lenses for management of keratoconus. Ophthalmol Clin North Am 2003;16:383-94.

3. Alio JL, Shabayek MH, Belda JI, et al. Analysis of results related to good and bad outcomes of INTACS implantation for keratoconus correction. J Cataract Refract Surg 2006;32:756-61.

4. Wollensak G, Spoerl E, Seiler T. Riboflavin/ultraviolet-a induced collagen crosslinking for treatment of keratoconus. Am J Ophthalmol 2003;135:620-7.

5. Wollensak G, Spoerl E, Seiler T. Treatment of keratoconus by collagen crosslinking. Ophthalmologe 2003;100:44-9.

6. Spoerl E, Huhle M, Seiler T. Induction of cross-links in corneal tissue. Exp Eye Res 1998;66:97-103.

7. Spoerl E, Seiler T. Techniques for stiffening the cornea. J Refract Surg 1999;15:711-3.

8. Wollensak G. Crosslinking treatment of progressive keratoconus: New hope. Curr Opinn Ophthalmol 2006;17:35660.

9. Wollensak G, Spoerl E, Seiler T. Stress-strain measurements of human and porcine corneas after riboflavin-ultraviolet-Ainduced cross-linking. J Cataract Refract Surg 2003;29:17805.

10. Rabinowitz YS. Keratoconus. Surv Ophthalmol 1998;42:297-
319.

11. Witta-Silva $\mathrm{C}$, Whiting $\mathrm{M}$, Lamoureux $\mathrm{E}$, et al. A randomized controlled trial of corneal collagen cross-linking in progressive keratoconus: Preliminary results. J Refract Surg 2008;24:720-5.

12. Kymionis GD, Diakonis VF, Kalyvianaki M, et al. One-year follow-up of corneal confocal microscopy after corneal crosslinking in patients with post laser in situ keratosmileusis ectasia and keratoconus. Am J Ophthalmol 2009;147:774-8.

13. Coskunseven E, Jankov MR, Hafezi F. Contralateral eye study of corneal collagen cross-linking with riboflavin and UV-A irradiation in patients with keratoconus. J Refract Surg 2009;25:371-6.

14. Gümüş K, Mirza E, Erkılıç K, et al. İlerleyici tip keratokonus hastalarında Ribo avin/UV-A ile çapraz bağlama tedavisinin erken dönem sonuçları. TOD Dergisi 2010;40:18-247.

15. Vinciguerra P, Albe E,Trazza S, et al.Refractive, topographic, tomographic, and aberrometric analysis of keratoconic eyes undergoing corneal cross-linking. Ophthalmology 2009;116:369-78.

16. Greenstein SA, Shah VP, Fry KL, et al. Corneal thickness changes after corneal collagen crosslinking for keratoconus and corneal ectasia: One-year results. J Cataract Refract Surg 2011;37:691-700.

17. Poli M, Cornut PL, Balmitgere T, et al. Prospective study of corneal collagen cross-linking efficacy and tolerance in the treatment of keratoconus and corneal ectasia: 3-year results. Cornea 2013;32:583-90.

18. Legare ME, lovieno A, Yeung $S N$, et al. Corneal collagen cross-linking using riboflavin and ultraviolet $A$ for the treatment of mild to moderate keratoconus: 2-year follow-up. Can J Ophthalmol 2013;48:63-8.

19. Goldich Y, Barkana Y, W Ussuku LO, et al. Corneal collagen crosslinking for the treatment of progressive keratoconus: 3-year prospective outcome. Can J Ophthalmol 2014;49:549.

20. Arbealez MC, Sekito MB, Vidal C, et al. Collagen crosslinking with ribo avin and ultraviolet $A$ light in keratoconus: One-year results. Oman J Ophthalmol 2009;2:33-8.

21. Henriquez MA, Izquierdo L Jr, Bernilla C, et al. Riboflavin/ Ultraviolet A corneal collagen cross-linking for the treatment of keratoconus: Visual outcomes and Scheimpflug analysis. Cornea 2011;30:281-6.

22. Tomita M, Mita M, Huseynova T. Accelerated versus conventional corneal collagen crosslinking. J Cataract Refract Surg 2014;40:1013-20.

23. Shetty R, Pahuja NK, Nuijts RM, et al. Current protocols of corneal collagen cross-linking: Visual, refractive and tomographic outcomes. Am J Ophthalmol 2015;160:243-9.

24. Shalchi Z, Wang X, Nanavaty MA. Safety and efficacy of epithelium removal and transepithelial corneal collagen crosslinking for keratoconus. Eye (Lond) 2015;29:15-29.

25. Poli M, Lefevre A, Auxenfans $C$, et al. Corneal collagen cross-linking for the treatment of progresive corneal ectasia: 6 year prospective outcome in a French population. Am J Ophthalmol 2015;160(4);654-62.

26. Li J, Ji P, Lin X. Efficacy of corneal collagen cross-linking for treatment of keratoconus: A meta-analysis of randomized controlled trials. P Lo S One 2015;10(5).

27. Abbouda A, Abicca I, Alio JL. Infectious keratitis followingcorneal crosslinking: A systematic review of reported cases: management, visual outcome and treatment proposed. 
Semin Ophthalmol 2014;13:1-7.

28. Kymionis GD, Bouzoukis DI, Diakonis VF, et al. Diffuse lamellar keratitis after corneal crosslinking in a patient with post-laser in situ keratomileusis corneal ectasia. J Cataract Refract Surg 2007;2135-7.

29. Ferrari G, Iuliano L, Vigano M, et al. Impending corneal perforation after collagen cross-linking for herpetic keratitis. J Cataract Refract Surg 2013;39:638-41.
30. Sharma A, Nottage JM, Mirchia K, et al. Persistan corneal edema after collagen crosslinking for keratoconus. Am J Ophthalmol 2012;154:922-6. 